\title{
Preparation and Characterization of poly-aniline hydrochloride (PANI-HCL) Nano-composites by Radiation
}

\author{
Moamar H. Idan ${ }^{\text {a }}$ Raheem G. Kadhim ${ }^{\text {b }}$ \\ ${ }^{a, b}$ Department of Physics, College of Science, University of Babylon, Iraq \\ moamar_h.idan1990@Yahoo.com_raheemnano2015@gmail.com
}

Submission date:- 9/7/2018 Acceptance date:- 4/9/2018 Publication date:- 28/1/2019

Keywords: poly-aniline hydrochloride, cobalt element, hall effect, current- voltages.

\begin{abstract}
During this search, the polymer poly-aniline hydrochloride (PANI-HCL) was prepared with different weights before and after irradiation in the form of films using the casting method. The films were recorded with the cobalt element $\left(\mathrm{CO}^{60}\right)$, which sends a gama (1.2) Mev for a period of (72) hours. The structural properties of the (FT-IR) were studied. The results showed that the active groups of the recorded polymer were consistent with the chemical composition and topographic study of the prepared film surfaces. The images showed that the recorded polymer is homogeneous and its color changes after irradiation.

The electrical properties included the measurement of the hall effect and the continuous electrical conductivity and the behavior of the current and voltages where the results showed that the hall coefficient of the polymer mixture recorded before and after the irradiation are carriers of the (n-type) and through the measurement of current- voltages show results that the polymer recorded conduct the behavior of ohmic before irradiation and walk Conduction of a semiconductor after irradiation. In addition, the results of electrical conductivity were shown to be less after irradiation.
\end{abstract}

\section{1-Introduction}

Polymers are materials which consist of alarge number of structural units by link of the same type [1]. Over the past few decades, as the polymers and plastics industry has very quickly [2]. By the end of 2000, near 200 million tons per year of plastic resources were formed universal (about $2 \%$ of the wood used, and nearly $5 \%$ of the oil harvested) to complete the ever-growing requirements of the plastic era, in the manufacturing world plastic equipment are used at a rate of nearly $100 \mathrm{~kg}$ per person per year. Plastic materials with over 250 billion dollars per year supply about $4 \%$ to the disgusting marital generate in the United States. Plastics have no complement in other equipment in conditions of weight, simplicity of manufacture, capable use, and finances [3]. Polymers have been entered in all parts of our lives. It is difficult to find affordable life with all services of services without the polymer industry [4].

\section{2- Poly-aniline Hydrochloride(PANI-HCL)}

The poly-aniline hydrochloride line series of numeric molecule (Oligomer), the poly aniline considers condction polymers the condctivity of it variance from $\left(10^{0}-10^{-10}\right) \mathrm{S} / \mathrm{cm}$. The method of oxidation and ionization for aniline $\left(\mathrm{C}_{6} \mathrm{H}_{5} \mathrm{NH}_{2}\right)$ in began nineteen century by the German scientific Willstter, the aniline can interact with acid chemical solution and based and result from this special compounds have important scientific applications .The general structural form to polymer show by the figure (1) [5].

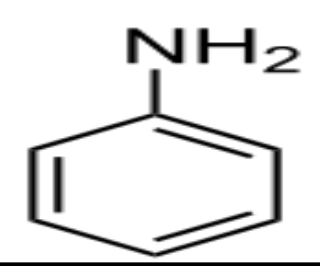

Fig. (1) Synthesis of poly-aniline(PANI). 


\section{3-Poly Vinyl Alcohol (PVA)}

Main physical features of poly vinyl alcohol (PVA) is water soluble, semi crystalline, nontoxic, biocompatible, eco-friendly, better film and fiber forming, good mechanical properties, excellent chemical resistance and biodegradable. The physical features of it produced by the polymerization of vinyl acetate to polyvinyl acetate (PVAC) and then hydrolysis to obtain of PVA. Poly vinyl alcohol (PVA) is a hydrophilic polymer which is serving special in application in medicine due to excellent biocompatibility and biodegradable. Finally,an important property of (PVA) is semicrystalline nature which is the existence of both amorphous and crystalline areas causing interfacial effects which increases the physical features. So, these unique characterizes of poly vinyl alcohol make it used in most commonly synthetic polymers [6]. PVA is commonly used in cosmetic, adhesive, food, paper, medicine, and packaging industries. The chief functional uses of poly vinyl alcohol involve filtration, optics, and catalysis. Several of the important properties of PVA are the result of its major cohesive energy because of polarity afrom group of hydroxyl that produce intra molecular of hydrogen bonding.

But, the same features that provide PVA with unique performance and hydrophobicity make it susceptible to plasticization in humid environments [7]. In addition to; the degree of swelling or rubbery in water or biological fluids is high [8].Polyvinyl alcohol has glass transition temperature $\mathrm{T}_{\mathrm{g}}=85^{\circ} \mathrm{C}$ and melting point temperature $\mathrm{T}_{\mathrm{m}}=$ $230^{\circ} \mathrm{C}$ and density is of $1.3\left(\mathrm{~g} / \mathrm{cm}^{3}\right)$ [15]. Figure (2) shows structure of polyvinyl alcohol.

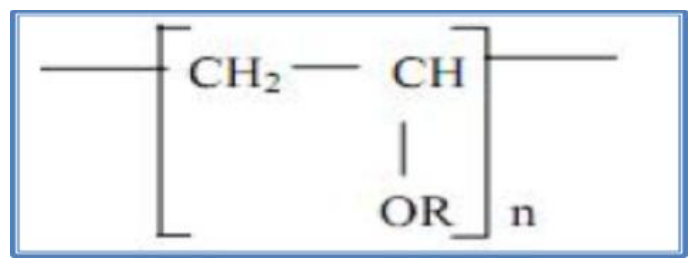

Fig. (2) structure of polyvinyl alcohol.

\section{4- Experimental Part}

4.1 The materials used in the search

a . poly-aniline(PANI).

b. Poly Vinyl Alcohol (PVA)

d. distilled water.

c. Slides of glass.

\section{2 Prepare polymer}

The polymer was prepared by dissolving the polyvinyl alcohol $(10 \mathrm{~g})$ in the distilled water $(90) \mathrm{ml}$. The polyaniline was added with different weight ratios (1,2 and $3 \mathrm{~g})$ to the (50) $\mathrm{ml}$ polyvinyl alcohol solution, where it was formed in the form of films using the casting method, then left to dry for (24) hours. After drying, it is exposed to irradiation using the cobalt $\left(\mathrm{CO}^{60}\right)$ element, which radiates a gama ray (1.2) MeV and has a half-life of (5.23) years for (3) days. Note that the irradiation process was conducted at the University of Babylon - College of Science Department of Physics.

\section{5- Electrical measurements}

The current-voltages of the poly-aniline hydrochloride polymer were measured before and after irradiation using 616C electrometer Keithly device at room temperature and by measuring current voltages the electrical conductivity was calculated and the behavior of current voltages.

\section{Theoretical calculations \\ 1.6 Hall Effect}

When a conductor is placed in a magnetic field and a current passed through it, an electric field will be produced, the direction of which is normal to both the current and magnetic field directions. This phenomenon, discovered by E.T. Hall in 1879, is known as the Hall effect [8].

The ratio of the voltage created is divided by the current and the magnetic field product by the element thickness, is called Hall coefficient $\left(R_{H}\right)$ which is known as a characteristic of the material from which the conductor is made, as its value depends on the type, number and properties of the charge carriers that constitute the current. When the magnetic field is applied perpendicular to the electric field, it yields a current (I) then the transverse (e.m.f), which is called Hall voltage $\left(\mathrm{V}_{\mathrm{H}}\right)$, is set up across the sample. So that Hall coefficient $\left(\mathrm{R}_{\mathrm{H}}\right)$ is given by [9]:

$\mathrm{R}_{\mathrm{H}}=\frac{\mathrm{V}_{\mathrm{H}}}{\mathrm{i}} \cdot \frac{\mathrm{t}}{\mathrm{B}}$

Where $\mathrm{t}$ : is the thickness of the film.

The carrier density $\left(\mathrm{n}_{\mathrm{H}}\right)$ is related to the Hall coefficient by the following equation[10]:

$n_{H}= \pm \frac{1}{q R_{H}}$ 
Where $\mathrm{q}$ : is the charge of electron, and it equals $\left(1.6 \times 10^{-19} \mathrm{C}\right)$

With the directions of control current and magnetic field illustrated in figure (3), the charge carriers which produce the current are deflected to the front edge of the sample; therefore, the current is mainly due to electrons ( as in the case of an n-type sample). The front edge becomes negatively charged. In the case of holes conduction ( $\mathrm{p}$ type sample) it becomes positively charged.

So from the sign of Hall coefficient $\left(\mathrm{R}_{\mathrm{H}}\right)$ equation (1), we can determine the type of semiconductor that we have used.

From $(\sigma)$ and $\left(\mathrm{R}_{\mathrm{H}}\right)$ we may determine the Hall mobility .

$\mu_{\mathrm{H}}=\sigma \times \mathrm{R}_{\mathrm{H}}$

or $\mu_{\mathrm{H}}$ equal:

$$
\mu_{\mathrm{H}}=\frac{\sigma}{\mathrm{n}_{\mathrm{e}} \mathrm{q}}
$$

Where $\left(\mathrm{n}_{\mathrm{e}}\right)$ is represented electron density.

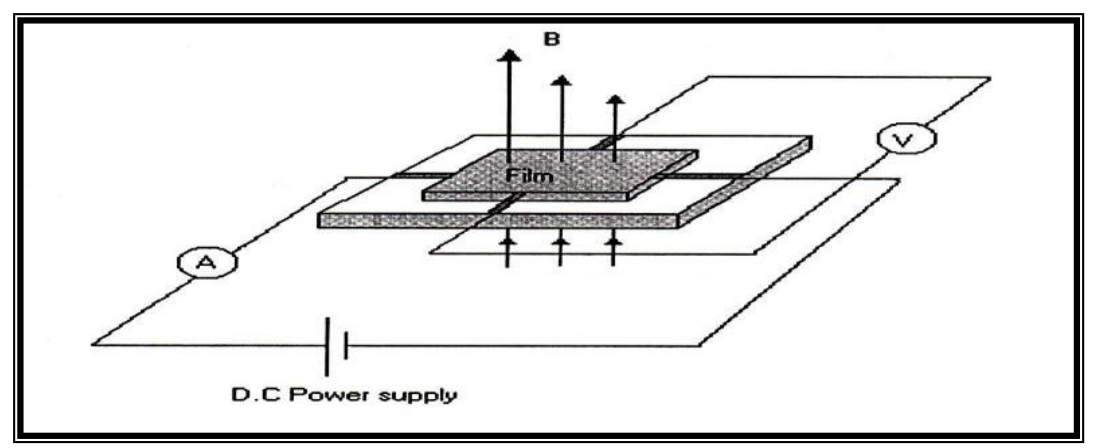

Fig. (3) The circuit used for the measurements of hall effect [80].

\subsection{D.C Electrical Properties}

In the recent years, the importance utilizing of polymers can be increased in the indistrial field as insulators due to of the polymers have high resistance and dielectric force. Therefore; polymers attracted attention of scientists for applications in electronic and optical fields. Choice of polymers depends on the insulator density and other physical properties in the range wide of temperature and frequency. So, the nature of charge transport in polymers must be understood by studying the electrical conduction in polymers. There are several mechanisms of conduction suggested for the charge transport as the Schottky effect, Pool-frenkel effect, space charge and hopping conduction limited conduction. To understand the numbers of the charge carrying species must be studies the D.C electrical properties of polymers. Chemical composition, morphology and microstructure of the material determined the parameters above [11].

\subsubsection{Electrical Resistivity}

In general, most of polymeric materials have very weak current by a direct voltage is applied. So, the electrical resistivity of most polymeric materials has a finite value. There are two types of resistance which are the current passing through the polymeric materials depending on them are [12].

1- The surface resistance of polymeric materials $\left(R_{S}\right)$ which is indicated current, can pass over the surface of polymeric materials. In addition to, which determines the presence of contaminates and moisture of the surface insulator.

2- The volumetric resistance of polymeric materials $\left(\mathrm{R}_{\mathrm{V}}\right)$ which the value determines the current pass through these materials.

The electrical conduction can be investigated either by the volume or across the surface of polymeric materials. The volumetric and the surface electrical resistivity can be determined by the insulator resistance. For a uniform body with a piece has a constant area (A), the length (l) and electrical resistance (R) to compute the resistance using the relation [13].

\section{$\mathrm{R}=\rho \frac{l}{\mathrm{~A}}$}

Where $\rho$ is the electrical resistivity.

It can be computed the volumetric electrical conductivity $\sigma_{\mathrm{V}}$ as:

$$
\sigma=\frac{l}{R A}
$$

The electrical resistivity is the value inverse to the electrical conductivity of polymers.

$\rho=\frac{1}{\sigma}$

By increasing of temperature, the electrical conductivity of polymers also increases exponentially according to the relation:

$$
\sigma=\sigma_{\mathrm{o}} \exp \left(-\mathrm{E}_{\mathrm{act}} / \mathrm{k}_{\mathrm{B}} \mathrm{T}\right)
$$




\subsection{6 -FT-IR Test}

The spectral measurements of the (FT-IR) of poly aniline-hydrochloride (PANI-HCL) before and after irradiation showed the absorption bundles shown in Table (1). Figure (4 and 5) shows the infrared absorption spectrum (FT-IR), which shows the chemical bonds in the polymer being prepared. The results showed that the sites of the active groups of the polymer were identical with their chemical composition.

Table(1) Absorption Packs for Poly-aniline - Hydrochloride (PANI - HCL).

\begin{tabular}{|c|c|}
\hline Absorption Packs 1/cm & Shaky group \\
\hline 3100 & $\left(\mathbf{N H}_{2}\right)$ \\
\hline 1475 & $(\mathbf{C}=\mathbf{C})$ \\
\hline 1350 & $(\mathbf{C}-\mathbf{N})$ \\
\hline 3150 & $(\mathbf{C}-\mathbf{H})$ \\
\hline 3650 & $(\mathbf{O H})$ \\
\hline 2850 & (C-H) Alibatics \\
\hline
\end{tabular}

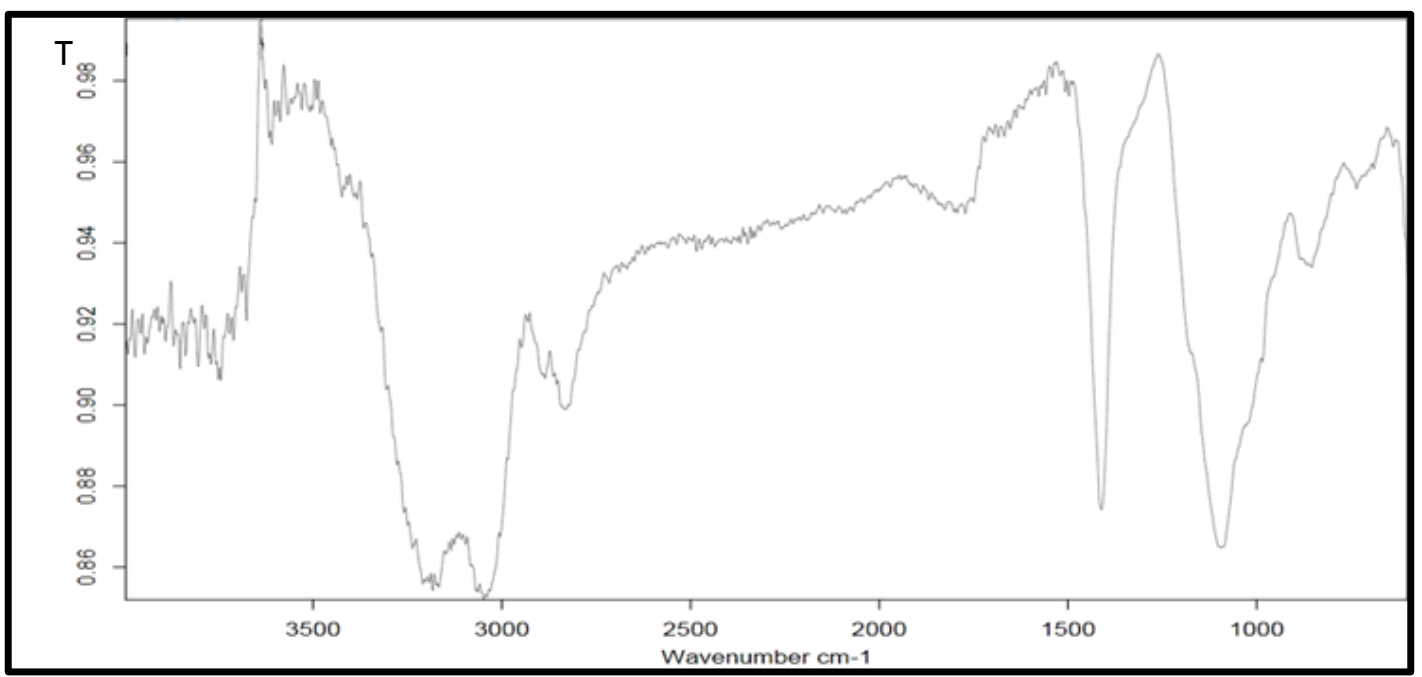

Fig. (4) (FT-IR) of non-irradiated poly- aniline hydrochloride compound.

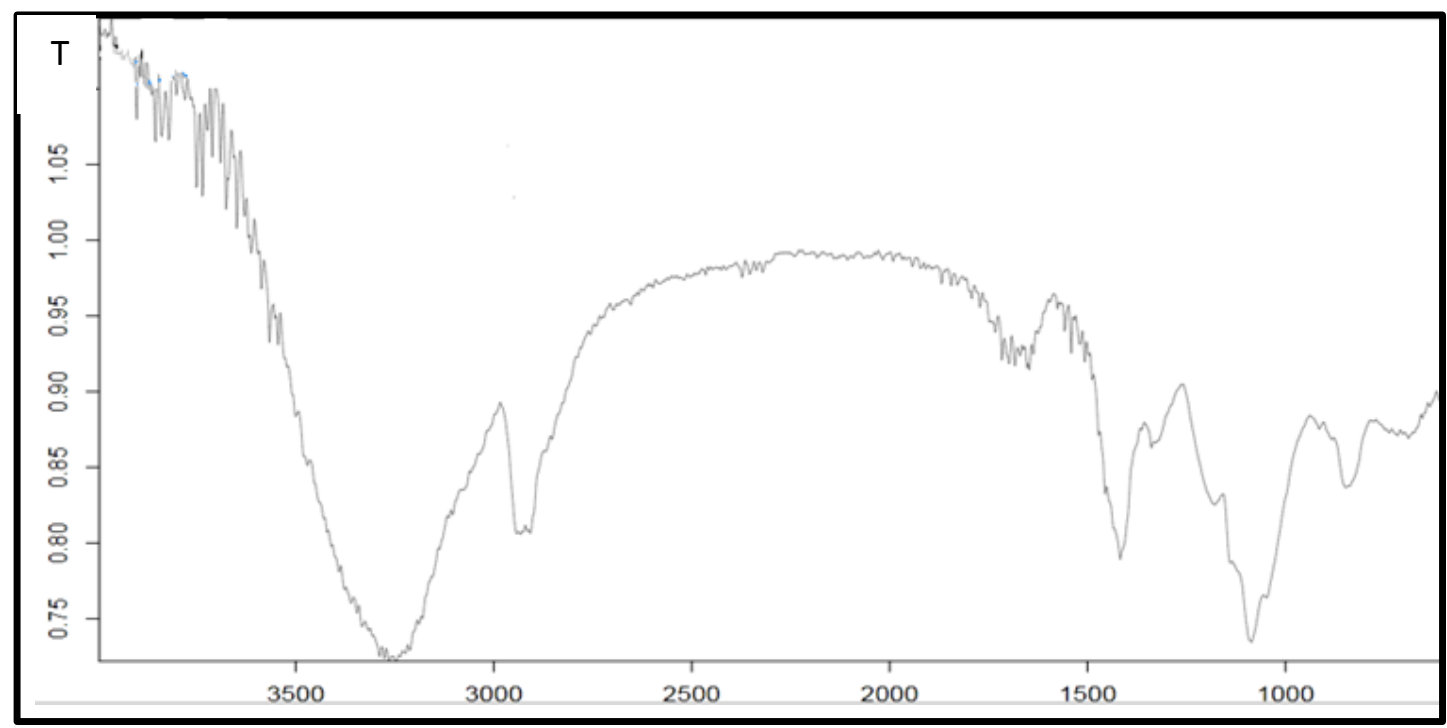

Fig. (5) (FT-IR) of irradiated poly- aniline hydrochloride compound. 


\subsubsection{Microscope Digital}

In order to study the topography of the films of the polymer film, polyniline hydrochloride before and after irradiation, the optical microscope was used with a camera with a magnification force of $1000 \mathrm{x}$. The intensity of the image is determined to determine the changes in the recorded polymer. Figure (6 and 7) indicate that the recorded polymer has a dendritic branch apolymorphic film in the process of polymerization and note through the images as homogeneous and without abrasions in addition there is a gradient color in the color of the polymer is proportional to the increase in the proportion of the weight of the mixture, which is prepared polymer. The process of irradiation led to a difference in the color of the polymer and the reason is due to the formation of double bonds because of the process of irradiation[14].

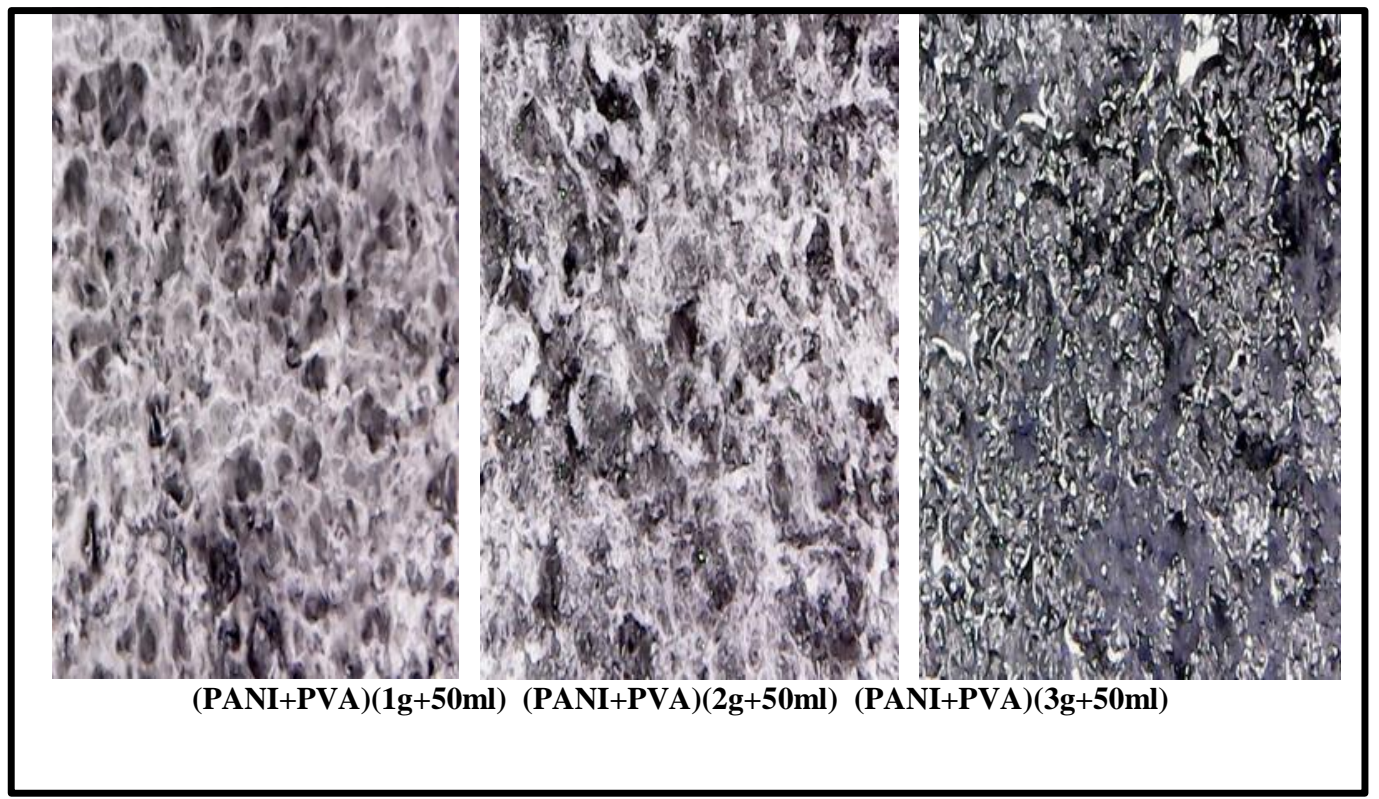

Fig. (6) shows the images of poly-aniline hydrochloride befor irradiation.

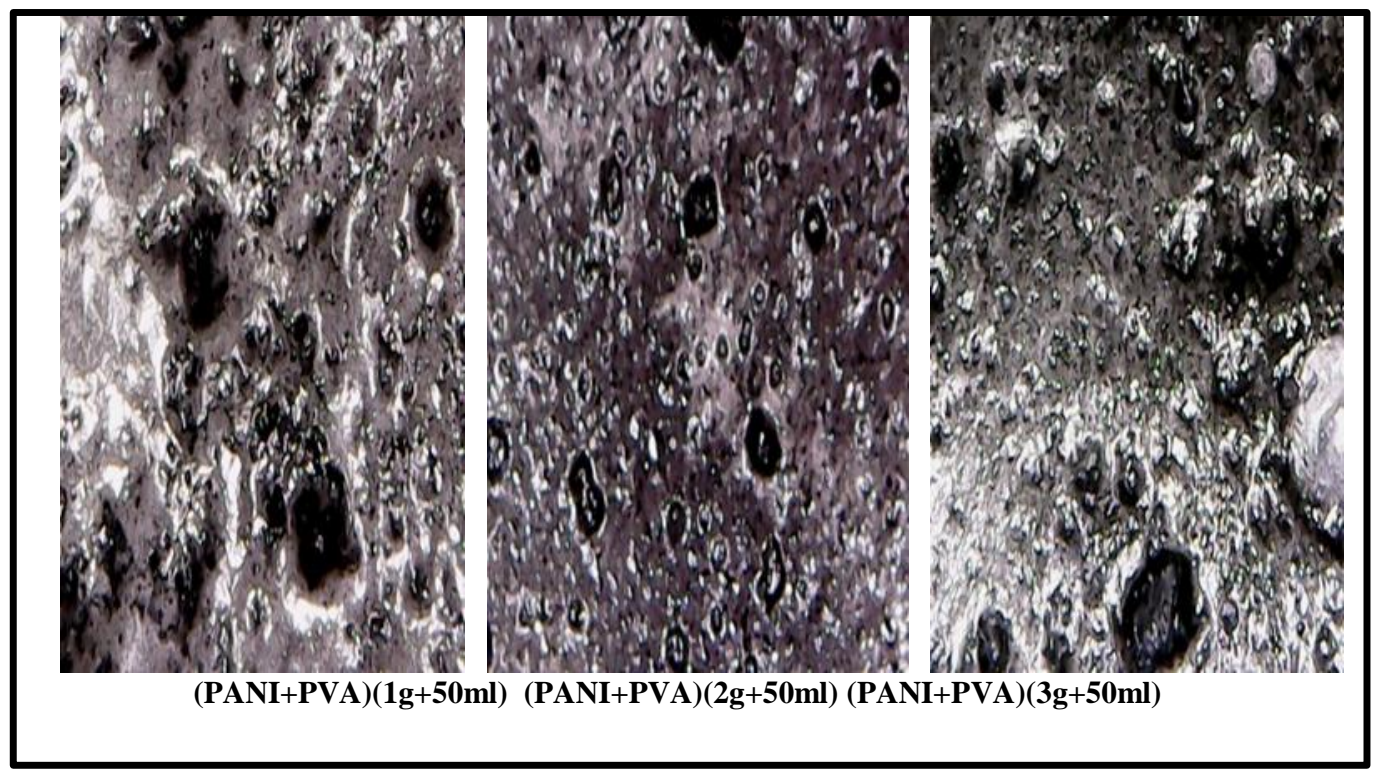

Fig. (7) shows the images of poly-aniline hydrochloride after irradiation.

\subsubsection{Hall effect measurements}

Hall effect measurements for the polymer films were obtained to obtain the value of the Hall coefficient and the electrical conductivity and polymer mobility at room temperature. Hall effect measurements were made to determine the Hall factor on the recorded films to determine Hall factor and the concentration of the carriers and the movement using Hall effect measurement system type HMS3000 manufactured by ECOPIA Taiwanese and using a magnetic field of magnitude $(\mathrm{B}=0.55$ tesla). 
The results showed that the Hall coefficient signal negative and this indicates that the carriers in the polymer n-type before and after irradiation due to the bonds of $\Pi$, and the values of the concentration of carriers and traffic increased values after irradiation, the values of resistance and the Hall coefficient and electrical conductivity decreased after irradiation, lead to improved electrical properties of the recorded polymer. Table (2) shows the results of the measurement of the Hall effect of the pre-irradiated polymer. Table (3) shows the results of the measurement of the Hall effect post-irradiation [15].

Table (2) Results of hall effect of the Poly-aniline hydrochloride polymer prior to irradiation.

\begin{tabular}{|c|c|c|c|c|c|}
\hline PANI+PVA & $\begin{array}{c}R_{\mathrm{H}} \\
\left(\mathrm{cm}^{-3} / \mathrm{C}\right)\end{array}$ & $\begin{array}{c}\mathrm{n}_{\mathrm{H}} \\
\left(1 / \mathrm{cm}^{3}\right)\end{array}$ & $\begin{array}{c}\rho \\
(\Omega . \mathrm{cm})\end{array}$ & $\begin{array}{c}\mu_{\mathrm{H}} \\
\left(\mathrm{cm}^{2} / \mathrm{V} . \mathrm{s}\right)\end{array}$ & $\begin{array}{c}\left(\sigma_{\mathrm{D} . \mathrm{C}}\right)_{\text {R.T }} \\
(\Omega . \mathrm{cm})^{-1}\end{array}$ \\
\hline $1 \mathrm{~g}+50 \mathrm{ml}$ & $-1.22 \times 10^{8}$ & $-5.09 \times 10^{10}$ & $4.71 \times 10^{6}$ & $3.01 \times 10^{1}$ & $5.45 \times 10^{-6}$ \\
\hline $2 \mathrm{~g}+50 \mathrm{ml}$ & $-8.96 \times 10^{7}$ & $-6.96 \times 10^{10}$ & $1.15 \times 10^{5}$ & $7.78 \times 10^{2}$ & $6.68 \times 10^{-6}$ \\
\hline $3 g+50 \mathrm{ml}$ & $-5.59 \times 10^{5}$ & $-1.11 \times 10^{10}$ & $1.94 \times 10^{4}$ & $2.88 \times 10^{2}$ & $8.15 \times 10^{-6}$ \\
\hline
\end{tabular}

Table (3) Results of hall Effect of the Poly-aniline hydrochloride polymer after irradiation.

\begin{tabular}{|c|c|c|c|c|c|}
\hline PANI+PVA & $\begin{array}{c}\mathbf{R}_{\mathrm{H}} \\
\left(\mathrm{cm}^{-3} / \mathrm{C}\right)\end{array}$ & $\begin{array}{c}\mathrm{n}_{\mathrm{H}} \\
\left(1 / \mathrm{cm}^{3}\right)\end{array}$ & $\begin{array}{c}\rho \\
(\Omega . \mathrm{cm})\end{array}$ & $\begin{array}{c}\mu_{\mathrm{H}} \\
\left(\mathrm{cm}^{2} / \mathrm{V} . \mathrm{s}\right)\end{array}$ & $\begin{array}{c}\left(\sigma_{\mathrm{D} . \mathrm{C}}\right)_{\text {R.T }} \\
(\Omega . \mathrm{cm})^{-1}\end{array}$ \\
\hline $1 \mathrm{~g}+50 \mathrm{ml}$ & $-4.052 \times 10^{7}$ & $-1.541 \times 10^{11}$ & $4.77 \times 10^{5}$ & $9.701 \times 10^{1}$ & $5.394 \times 10^{-7}$ \\
\hline $2 \mathrm{~g}+50 \mathrm{ml}$ & $-4.597 \times 10^{7}$ & $-1.358 \times 10^{11}$ & $1.065 \times 10^{5}$ & $8.761 \times 10^{2}$ & $5.006 \times 10^{-7}$ \\
\hline $3 g+50 \mathrm{ml}$ & $-1.599 \times 10^{5}$ & $-3.904 \times 10^{11}$ & $1.617 \times 10^{3}$ & $6.109 \times 10^{2}$ & $7.821 \times 10^{-7}$ \\
\hline
\end{tabular}

\subsubsection{Electrical Conductivity (D.C)}

Continuous electrical conductivity was measured for all weight ratios of the poly-aniline hydrochloride polymer recorded before and after irradiation according to equation (6). In Table (4) we observe that the electrical conductivity values of the polymer are increased by increasing the weight ratio. The increase in the weight ratio leads to an increase in the number of ions and free electrons on a regular basis, which increases the interaction between the mixture particles, which in turn leads to disturbance within the mixture. Conductivity. As for the effect of the irradiation process, there was a decrease in the values of the electrical conductivity compared to their values before irradiation due to the increase of the interferometry rate due to the irradiation effect which in turn restricts the movement of the charge carriers in the recorded polymer [16],[17].

Table $(4)$ shows the electrical conductivity $\left(\sigma_{\text {D.C }}\right)$ values of the poly-aniline hydrochloride polymer

\begin{tabular}{|c|c|c|}
\hline \multicolumn{3}{|c|}{$\left(\sigma_{\text {D.C }}\right)(\Omega . c m)^{-1}$} \\
\hline PANI+PVA & Non-radiated & Irradiated \\
\hline $1 \mathrm{~g}+50 \mathrm{ml}$ & $1.458 \times 10^{-6}$ & $1.382 \times 10^{-7}$ \\
\hline $2 \mathrm{~g}+50 \mathrm{ml}$ & $1.556 \times 10^{-6}$ & $1.435 \times 10^{-7}$ \\
\hline $3 \mathrm{~g}+50 \mathrm{ml}$ & $1.655 \times 10^{-6}$ & $1.546 \times 10^{-7}$ \\
\hline
\end{tabular}




\subsubsection{Current -Voltage Behavior}

The current-voltages of the poly-aniline hydrochloride polymer were measured before and after irradiation . Figure(8) shows the current-voltmeter curves of the poly-aniline hydrochloride polymer recorded before irradiation. Note that when the voltages increase, the current increase is almost constant. The current change in voltages with the current is an ohmic change in the conductive material. This is expected to occur because the mixture from which the polymer is present contains On poly-aniline it is a material conductive material. Figure (9) shows the curves of the current-current of the polymer poly-aniline hydrochloride recorded from the mixture after irradiation. At low voltages $(\mathrm{V}<0.5 \mathrm{~V})$, the transmission of the charge across the material is very low and therefore the current is very small or zero, either when the voltages are increased to a certain limit $(\mathrm{V}>0.5 \mathrm{~V})$ the process begins with a collapse in the semiconductor so we notice a rapid increase in current, that the moment of collapse is the release of a large number of electrons are available for the passage of the current due to the irradiation process that leads to broken bonds and this leads to increased concentration of the voltage vector in the semiconductor. Note that the polymer recorded from the mixture behaves the behavior of the ohmic before irradiation while the behavior of exponential or semiconductor after irradiation is due to the increase of tangled due to the effect of the irradiation process, which leads to the restriction of movement of carriers in the polymer in addition to note the electrical connection less after irradiation and this guide the polymer (PANI-HCL) exhibits a semiconductor conduct after irradiation [17],[18]. 


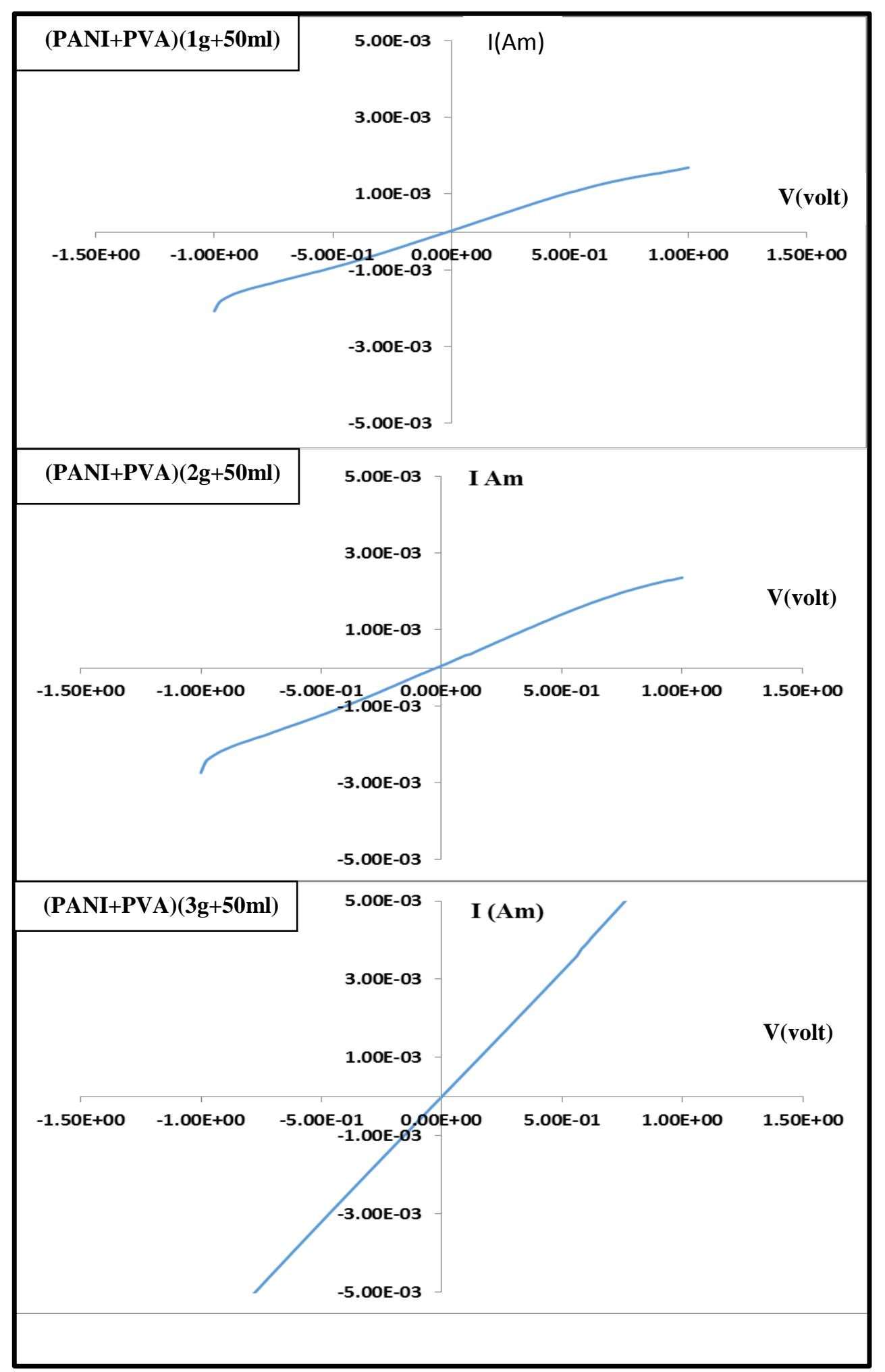

Fig. (8) Current -voltage of the poly-aniline hydrochloride (PANI-HCL) polymer before irradiation. 


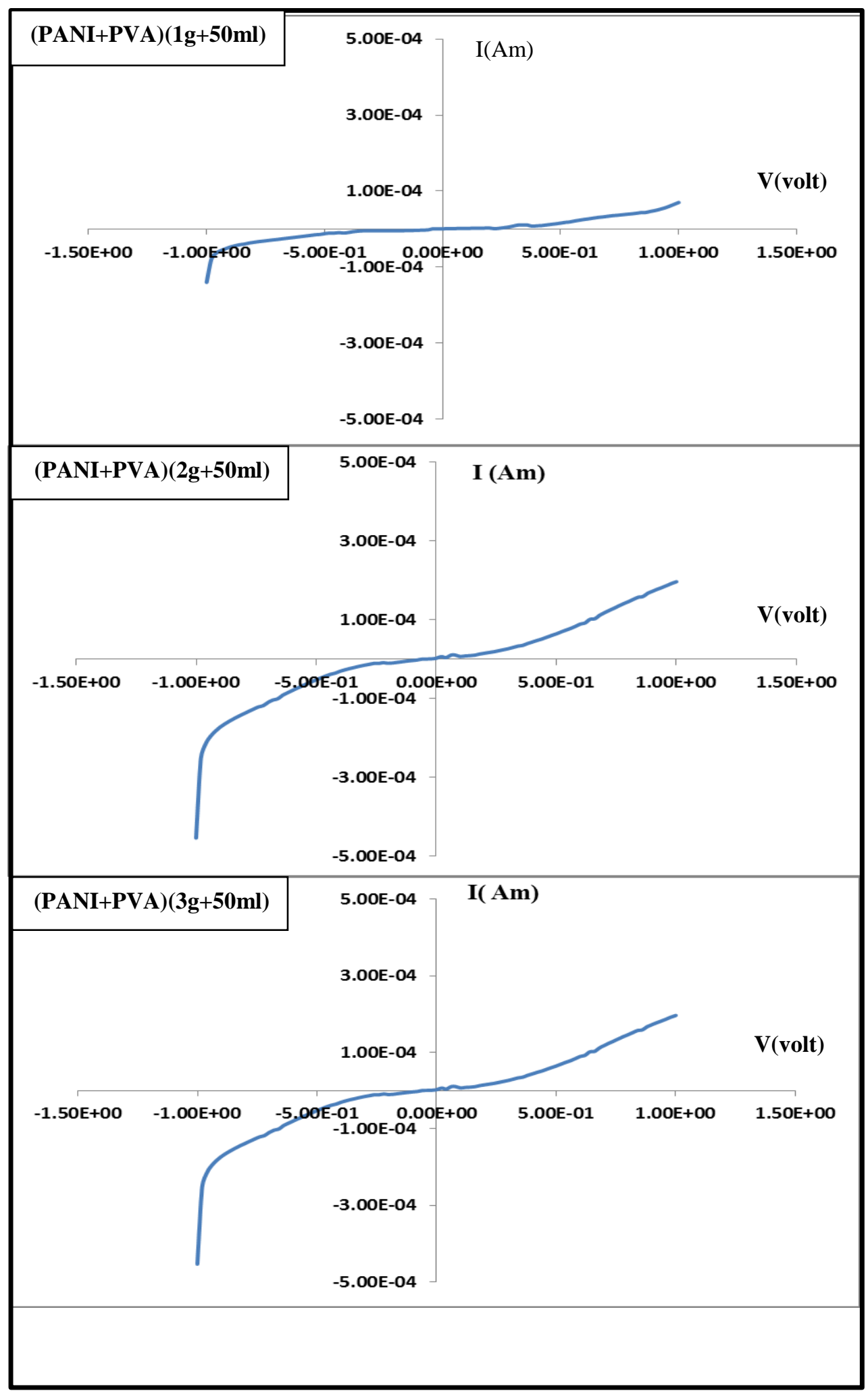

Fig. (9) Current -voltage of the poly-aniline hydrochloride (PANI-HCL) polymer after irradiation 


\section{7- Conclusions}

1- Poly aniline hydrochloride polymer changes color gradually after irradiation.

2- The irradiation process did not change the type of the charge carriers in the prepared polymer, but kept the cargo carriers of (n-type).

3- The recorded polymer behaves as a maternal behavior before irradiation and behaves as a semiconductor after irradiation.

4- The process of irradiation affected the electrical conductivity as it decreased after irradiation.

\section{CONFLICT OF INTERESTS}

There are no conflicts of interest.

\section{8- References}

[1] E. Charles , Jr.Carraher, ," Polymer Chemistry", Sixth Edition , U.S.A New York, 2003.

[2] L.Sperling , "Introduction to Physical Polymer Science", University of Bethlehem, Pennsylvania, $4^{\text {th. }}$ Ed., p. (1), 2006.

[3] R.H.Colby and M. Rubinstein , "Polymer Physics ", Oxford University (U.S.A.), 2003.

[4] S. Mustafa ,"Engineering Chemistry", Lib. of Arab Society for Publication and Distribution , Jordan, 2008.

[5] D.Barton, W.D.Ollis " Comprehensive Organic Chemistry "1 ${ }^{\text {st }}$ Ed. Pregman Press Oxford, Vol. 21979.

[6] Jolanta S., Mārtinš̌ K., Anda D. and Velta T.," Polyvinyl alcohol hydrogels", Proceedings of the Estonian Academy of Sciences ,Vol 58,No. 1,pp.63-66 2009.

[7] Mudigoudra B.S., Masti S.P., Chougale R.B.,"Thermal Behavior of Poly (vinyl alcohol)/ Poly (vinyl pyrrolidone)/ Chitosan Ternary Polymer Blend Films", Research Journal of Recent Sciences, Vol.1,No.9, pp.83-86 2012.

[8] Look D.C.," Methods in Materials", Research 5a 2.1-5a 2.8 Wiley, New York, p. 15, 2000.

[9] S.K.Jemil, B.D.Blawah, "Principles of electronic optics", Baghdad University 1991.

[10] N.P. Bogoroditsky, V.V. Pasnkov \& B.M. Tareev, ‘ Electrical Engineering Materials’ 1979.

[11] S. D. Ganichev, E. Ziemann, and W. Prettl," Distinction between the Poole-Frenkel and tunneling models of electric-field-stimulated carrier emission from deep levels in semiconductors",Journal of The American Physical Society, Vol. 61, No.15,pp.362-364 2000.

[12] William D. Callister, Jr.," materials science and engendering ", $7^{\text {th }}$ Edition, USA, 2007.

[13] Donald A. Neamen.," Semiconductors physics and devices ", $3^{\text {rd }}$ Edition,USA 2003.

[14] ALI,ABDUL KHABEER ALI; "polymer surface modifcation by laser", university of Baghdad 2005.

[15] Hua Bai and Gaoquan Shi. 2015. Gas Sensors Baased on Conducting polymers Sensors. 2007,7:267-307.

[16] M. N.Obaid and S. M. Hassan " A.C electrical properties of pure and doped polyaniline salt prepared by electro-chemical polymerization", Advances in Environmental Biology, Issue 11, Vol. 2, pp. (17-26), 2017.

[17] W. Wanga and E. A. Schiff, " Polyaniline on crystalline silicon heterojunction solar cells ", Applied Physics Letters 91, pp. (133504-133506), 2007.

[18] A. Mehto,V. Mehto,J. Chauhan,I. Singh and R .Pandey," Preparation and Characterization of Polyaniline/ZnO Composite Sensor", Journal of Nanomedicine Research, Vol. No. 1, 2017. 


\section{تحضير وتثخيص المركب النانوي البولي انيلينهيدروكلورايد(PANI-HCL) بالتشعيع}

تم تحضير البوليمر البولي انيلين هيدروكلورايد بنسب وزنية مختلفة قبل وبعد التشعيع على شكل افلام باستخدام طريقة الصب ،حيث شعت

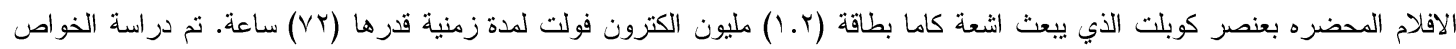

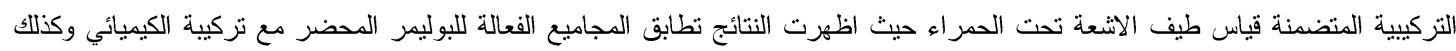

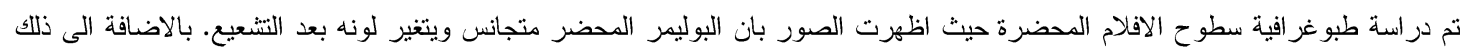

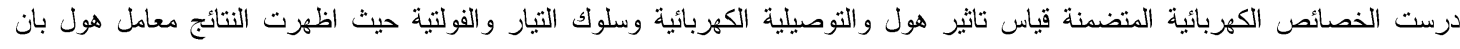

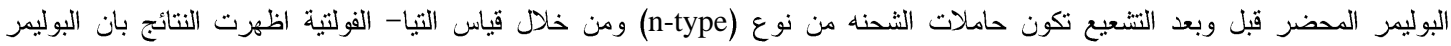
المحضر يسلك سلوك اومي قبل التشعيع ويسلك سلوك شبه موصل بعد التتعيع ،بالاضافة الى ذلك اظهرت نتائج التوصيلية الكهربائية بانها تقل بعد التشعيع. الكلمات الدالة: البولي انيلين هيدروكلور ايد, عنصر الكوبلت, تاثير هول, التيار -الفولتية. 